\title{
Estudio sobre la economía circular como una alternativa sustentable frente al ocaso de la economía tradicional (primera parte)
}

\section{Study on the Circular Economy as a Sustainable Alternative to the Decline of the Traditional Economy (First Part)}

Adriana Norma Martínez* y Adriana Margarita Porcelli**

http://dx.doi.org/10.21503/lex.v16i22.1659

* Abogada, escribana, posgraduada en Derecho del Turismo UBA. Magíster en Ambiente Humano. UNLZ. Profesora adjunta regular en el Departamento de la Facultad de Derecho de la Universidad de Buenos Aires. Jefa de la División de Derecho. Profesora asociada ordinaria de la Universidad Nacional de Luján.

Correo electrónico: info@anmart.com.ar

** Abogada UBA. Magíster en Relaciones Internacionales por la Universidad Maimónides. Diplomada en Derechos Económicos, Sociales y Culturales, UNPSJB. Profesora adjunta ordinaria de la División de Derecho de la Universidad Nacional de Luján.

Correo electrónico: adporcelli@yahoo.com.ar

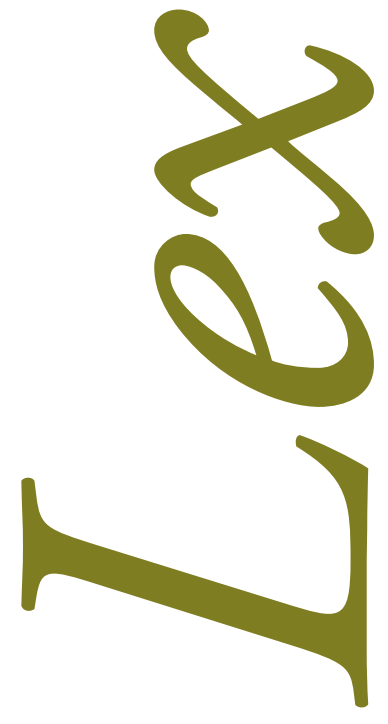




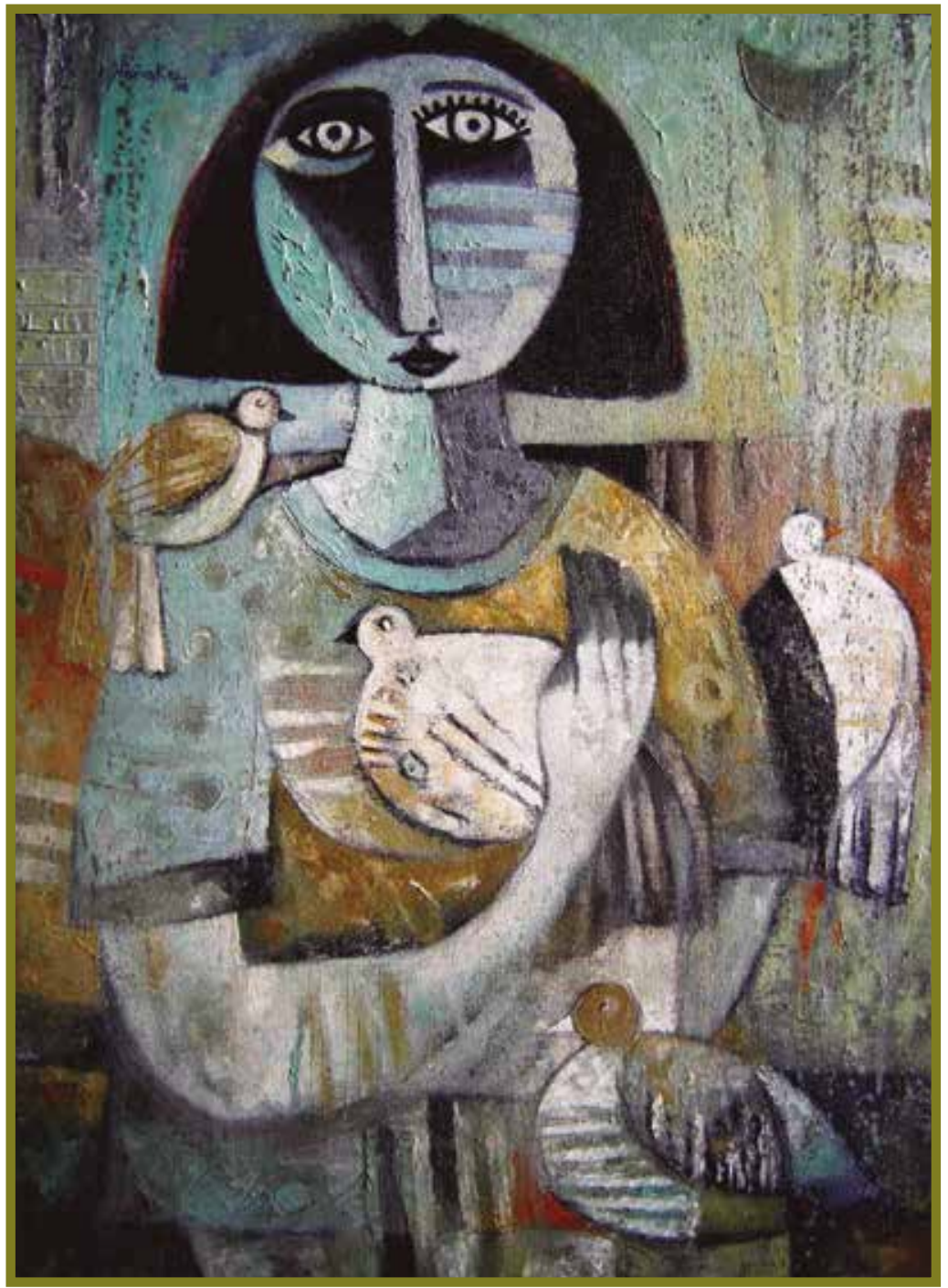

Silencio. Pintura. Juan Carlos Nananake. 


\section{RESUMEN}

En las últimas décadas, el modelo económico actualmente predominante — denominado "economía marrón"- ocasionó el agotamiento de los recursos naturales y la degradación y pérdida generalizadas de los ecosistemas, lo cual ha dado espacio para que surja un modelo económico alternativo denominado la economía verde, y dentro del mismo, la economía circular. Una economía de ciclos cerrados, que imita los de la naturaleza para que sea más eficiente, racional y equilibrada, incorporando los esquemas de análisis del ciclo de vida de los productos, reutilizando los residuos. El presente trabajo forma parte de una investigación que analiza, entre otros, los impactos ambientales de la obsolescencia programada y la economía verde, desarrollada en el Departamento de Ciencias Sociales de la Universidad Nacional de Luján. El objetivo de este trabajo consiste en analizar, en primer lugar, si la economía circular es una alternativa fiable y plausible para desarrollar un nuevo modelo que permita propiciar una cultura altamente sustentable y respetuosa del ambiente, sus pilares, las más destacadas prácticas empresariales y gubernamentales, a ese respecto, en el mundo y en Argentina, y, en segundo lugar, su recepción en las diferentes legislaciones y en la normativa voluntaria. Debido a la extensión del tema, el mismo se expone en dos partes y el presente artículo constituye la primera parte que desarrolla los principios y pilares fundamentales de la economía circular, analiza los argumentos de sus defensores como de sus detractores y exterioriza las prácticas empresariales más significativas en Argentina.

Palabras clave: economía circular, reutilización, reparación, reciclaje, residuos.

\section{ABSTRACT}

In recent decades, the currently predominant economic model - called the "brown economy" - has led to the depletion of natural resources and the widespread degradation and loss of ecosystems, which has given rise to an alternative economic model called the green economy and within it the circular economy. A closed-loop economy, which imitates those of nature in order to make it more efficient, rational and balanced, incorporating life-cycle analysis schemes for products and reusing waste. This work is part of a research project that analyses, among others, the environmental impacts of planned obsolescence and the green economy, carried out at the Department of Social Sciences of the National University of Luján. The objective of this paper is to analyze, firstly, if the circular economy is a reliable and plausible alternative to develop a new model to promote a highly sustainable and environmentally friendly culture, its pillars, the most outstanding business and government practices, in this respect, in the world and in Argentine, and, secondly, its reception in the different legislations and standarization. Due to the extension of the 
topic, it is presented in two parts and this article is the first part that develops the fundamental principles and pillars of the circular economy, analyzes the arguments of its defenders as well as its detractors and externalizes the most significant business practices in Argentine.

Key words: circular economy, reuse, repair, recycling, waste. 


\section{INTRODUCCIÓN}

En las últimas décadas, el crecimiento económico, el desarrollo industrial y las modernas tecnologías han aportado un nuevo grado de confort y bienestar a nuestra vida, ocasionando un aumento del consumo de bienes y servicios. Sin embargo, este crecimiento se logró a expensas del agotamiento de los recursos naturales, en especial del consumo desmedido de muchos minerales. El informe del Departamento de Asuntos Económicos y Sociales de Naciones Unidas World Population Prospects. The 2017 Revision (en español "Revisión de las Perspectivas de Población Mundial") indica que hay un $95 \%$ de probabilidades de que la actual población mundial, de 7600 millones de habitantes a mediados del 2017, se sitúe entre los 8400 y 8700 millones en 2030, entre 9400 y 10200 millones en 2050, y entre 9600 y 13200 millones en 2100. Aproximadamente, cada ańo se ańaden 83 millones de personas a la población mundial, y se espera que continúe la tendencia en alza, aun suponiendo que los niveles de fecundidad sigan disminuyendo ${ }^{1}$. Por tanto, y ante esta situación, surgen, con renovada fuerza, planteamientos para afrontar el necesario cambio de paradigma de la economía convencional mediante un nuevo modelo de producción y consumo sostenible. Así se plantea una nueva economía ecológicamente racional, ecoeficiente e inclusiva, actuando sobre las causas fundamentales de los desequilibrios, vale decir, sobre las actuales pautas económicas no solo de producción y consumo, denominada economía verde, que ha constituido un eje fundamental en la Conferencia de la Naciones Unidas sobre el Desarrollo Sostenible de 2012 (comúnmente conocida como la Cumbre de Río +20) tal como ha quedado plasmado en su documento final denominado El Futuro que Queremos. La delimitación del concepto economía verde, green economy, no es simple, pero se puede afirmar que es un conjunto de modelos de producción integral que toma en consideración variables ambientales y sociales, produce bajas emisiones de carbono, utiliza los recursos de forma eficiente y es socialmente incluyente. $^{2}$

1 United Nations, Department of Economic and Social Affairs, Population Division, World Population Prospects: The 2017 Revision, Key Findings and Advance Tables (New York: United Nations, 2017), 1.

2 Programa de las Naciones Unidas para el Medio Ambiente, Hacia una economía verde: Guia para el desarrollo sostenible y la 
El objetivo del presente trabajo consiste en analizar, en el marco de la economía verde, ${ }^{3}$ si la economía circular es una alternativa fiable y plausible para desarrollar un nuevo modelo que permita propiciar una cultura sustentable y respetuosa del ambiente y su recepción en las diferentes legislaciones y en la normativa voluntaria en lo que concierne a la gestión de los recursos naturales al incremento de la eficiencia energética, a la reducción de las emisiones de gas carbono, al desarrollo de productos y servicios verdes, a la gestión de desperdicios y a la utilización de tecnologías altamente limpias. Se propone recrear la "economía de la naturaleza”, incorporando los esquemas de análisis del ciclo de vida de los productos, reutilizando los residuos. Con esta perspectiva se alienta un proceso de transformación estructural desde un enfoque lineal a uno circular, para lo cual es necesario un cambio de filosofía y de la relación entre el hombre y la naturaleza y entre los consumidores y las cosas.

La metodología adoptada se relaciona con la observación documental y el análisis del contenido en base a la triangulación de la información de las distintas fuentes proveniente de todas las áreas comprendidas, y consistió en el relevamiento, revisión y sistematización de la bibliografía existente sobre el tema, la elaboración y clasificación de conceptos teórico-técnicos específicos y la identificación, a partir del relevamiento, recopilación y sistematización metódica, de las buenas prácticas empresariales y gubernamentales.

\section{DEBATE: LA ECONOMÍA CIRCULAR}

\section{Transición de la economía lineal a la circular}

El sistema de producción vigente se basa principalmente en un proceso lineal de consumo de recursos. Bajo el paradigma "take-make-waste" ("extraer-fabricar-consumir-eliminar"), los bienes son producidos a partir de las materias primas, luego vendidos, utilizados y finalmente desechados como residuos, ocasionando no solo el agotamiento de los recursos naturales sino también la generación de toneladas de basura. Alrededor de 65 mil millones de toneladas de materias primas entraron al sistema económico en 2010, y se espera que esta cifra crezca en 82 mil millones de toneladas en el 2020. Es muy probable que el panorama mundial se agrave, ya que la clase media global se multiplicará más que por dos de aquí a 2030, hasta alcanzar prácticamente los 5 mil millones de personas que se sumarán a los hábitos del consumo. ${ }^{4}$

erradicación de la pobreza - Sintesis para los encargados de la formulación de políticas (New York: Programa de las Naciones Unidas para el Medio Ambiente, 2011), 1-2.

3 Para profundizar en la temática de economía verde, características y beneficios, véase Adriana Martínez y Adriana Porcelli, "Reflexiones sobre la Economía Verde. El New Deal Ecológico Mundial", Revista de la Facultad de Derecho y Ciencia Politica de la Universidad Alas Peruanas 15, 19 (2017): 361-408, doi: http:// dx.doi.org/10.21503/lex.v15i19.1383

4 Ellen MacArthur Foundation, Hacia una economía circular. Resumen Ejecutivo (Reino Unido: Ellen MacArthur Foundation, 2014), 2-3. 
En consecuencia, se pueden identificar las siguientes limitaciones al modelo lineal tan cuestionado: a) riesgos de precios: hacia finales del milenio los precios de los recursos naturales comenzaron a ascender y mientras la población crecerá, la urbanización se incrementará y los costos continuarán en aumento; b) pérdidas económicas y residuos estructurales: la economía actual genera una gran cantidad de residuos. Por ejemplo, un automóvil se pasa el $92 \%$ del tiempo estacionado y el $31 \%$ de los alimentos se desechan a lo largo de la cadena de valor, ${ }^{5}$ c) riesgos de suministro: muchas regiones del mundo poseen pocos depósitos naturales de recursos no renovables propios, por lo que dependen de las importaciones, y d) deterioro de los sistemas naturales: dentro de los impactos ambientales se pueden enumerar, entre otros, el agotamiento de las reservas, la reducción de la capa de ozono, el cambio climático, la disminución de la biodiversidad, la degradación del suelo y la contaminación de los océanos.

En este contexto, cada vez son más voces las que se suman para reclamar un cambio de modelo industrial que desvincule los ingresos del consumo de materias primas y que sea capaz de ofrecer sistemas económicos resilientes: a esto apunta la economía circular.

\section{Antecedentes de la economía circular. Escuelas de pensamiento}

Las grandes escuelas de pensamiento relacionadas con la economía circular surgieron en los años 70, gracias a un pequeño número de académicos, líderes de pensamiento y empresas, pero recién a partir de la década de los 90 cobraron prominencia. A continuación, se mencionarán las principales filosofías que confluyeron en el modelo circular:

1) Diseño Regenerativo (Regenerative Design): John T. Lyle, profesor Universidad P. de Pomona (California), postuló que cualquier sistema — partiendo de la agriculturase puede organizar de forma regenerativa, emulando el funcionamiento de los ecosistemas, donde los productos se crean e interaccionan sin producir residuos. ${ }^{6}$ Podría decirse que sentó las bases del marco de la economía circular, que se desarrolló especialmente y ganó notoriedad gracias a McDonough, Braungart y Stahel.

2) Economía del Rendimiento (Performance Economy): en 1976, el arquitecto y economista Walter Stahel, acreditado por ser el inventor de la expresión "Cradle to Cradle" (de la cuna a la cuna), esbozó la visión de una economía en bucles - o economía circular-y su impacto en la creación del empleo, en la competitividad económica, en el ahorro de recursos y en la prevención de residuos. Persigue cuatro objetivos principales: la extensión de la vida del producto, los bienes de larga duración, las actividades de

5 Ellen MacArthur Foundation, Growth Within: a circular economy vision for a competitive Europe (Reino Unido: Ellen MacArthur Foundation, SUN, McKinsey \& Co., 2015), 13-15.

6 John Lyle, Regenerative Design for Sustainable Development (New York: Wiley and Sons, 1994). 
reacondicionamiento y la prevención de residuos. Además, insiste en la importancia de la venta de servicios en lugar de productos. ${ }^{7}$

3) De la Cuna a la Cuna. Cradle to Cradle. C2C: el químico y visionario alemán Michael Braungart desarrolló, junto con el arquitecto estadounidense Bill McDonough, el concepto Cradle to Cradle (de la cuna a la cuna) en oposición a cradle to grave (de la cuna a la tumba) propio de la economía lineal. En el año 2002 publicaron el libro De la cuna a la cuna. Rediseñando la forma en que hacemos las cosas (en inglés: Cradle to Cradle: Remaking the Way We Make Things) en cual exponen una nueva forma de interpretar el ecologismo, o como la denominan: la próxima Revolución Industrial. A diferencia de la consigna principal del ecologismo centrada en "reducir, reutilizar y reciclar", estos autores plantean un cambio de premisa, proponiendo que se aborden los problemas desde su misma raíz, vale decir, que los productos se diseñen y conciban sin necesidad del gasto de energía, incluso que el balance de gastos y aportes sea positivo. ${ }^{8}$ Esta filosofía de diseńo considera a los materiales involucrados en los procesos industriales y comerciales como nutrientes, clasificándolos en técnicos y biológicos. Los pilares en los cuales se asienta esta filosofía básicamente son: a) eliminar el concepto de residuos: parten de la premisa de que los residuos equivalen a alimentos. En los ecosistemas del planeta, no existe la basura, por tanto, la sociedad puede hacer lo mismo diseñando todos los productos, de modo que los materiales se reciclen en el mismo uso, o bien se reciclen "hacia arriba", es decir que el siguiente uso tenga más valor que el actual. Los productos y procesos se diseñan para ser indefinidamente retomados por la naturaleza (biosfera) o por las fábricas (tecnosfera), pasando del actual sistema de reciclaje imperfecto e insuficiente al upcycling; ${ }^{9}$ b) hacer uso de la energía renovable, y c) celebrar la diversidad: gestionar el uso del agua para maximizar la calidad, promover ecosistemas saludables y respetar los efectos a nivel local. En consecuencia, persigue ayudar a crear una mejor sociedad más allá de la idea de sostenibilidad convencional, a partir del buen diseño de productos, bienes y servicios. ${ }^{10}$

4) Ecología industrial (Industrial Ecology IE): a menudo denominada "ciencia de la sostenibilidad", tiene sus orígenes contemporáneos en un artículo publicado en 1998

Walter Stahel. The Performance Economy (Hampshire: Palgrave Macmillan, 2010).

8 Llevado a un ejemplo práctico, esto implicaría que si un edificio gasta mucha energía en aire acondicionado e iluminación, además de optimizar el rendimiento de la maquinaria y la instalación de paneles fotovoltaicos, el mismo se diseñe desde su inicio planteándose el aprovechamiento de la ventilación cruzada y de la iluminación natural, incluso el edificio generaría más energía de la que consumiera.

9 El Upcycling es un término acuñado recientemente, también conocido como suprarreciclaje, que consiste en aprovechar materiales reciclables para crear productos que tienen un mayor valor que el que tenía el material original, vale decir, transformar residuos en objetos de valor.

10 Michael Braungart y William McDonough, Cradle to Cradle (De la cuna a la cuna): rediseñando la forma en que hacemos las cosas (Madrid: McGraw-Hill, 2005). 
intitulado "Strategies for Manufacturing" de Robert Frosch y Nicholas Gallopoulos. Consiste en un enfoque del diseño industrial de productos y procesos buscando que se utilicen de manera más eficiente los recursos, que se mejore la calidad de vida humana y ambiental y que resurja ante todo la equidad social. Por otra parte, pretende que los actuales sistemas industriales se organicen de manera más equilibrada, para obtener productos o sustancias cuyo consumo satisface sus necesidades, haciendo posible la supervivencia del sistema. Adopta un punto de vista sistémico, diseñando los procesos de producción atendiendo a las restricciones ecológicas tratando de darles forma para que sean lo más parecido posible a los sistemas vivos. Finalmente, la ecología industrial no solo apunta hacia los temas de contaminación y ambiente, sino que revisten igual importancia las tecnologías, la economía de los procesos y la interrelación entre los negocios, financiación y política gubernamental, por lo cual no solo se presenta como una opción efectiva para la protección del ambiente, sino también para optimizar el uso de los recursos naturales no renovables. En consecuencia, presenta como novedad la capacidad de combinar los estudios de cada sector mediante procesos integradores, para lo cual requiere del dominio de disciplinas muy diversas como la ingeniería, física, química, ecología, derecho, economía, filosofía y ecodiseño. ${ }^{11}$

5) Biomimesis (“Biomimicry”): es la disciplina científica que estudia a la naturaleza como fuente de inspiración. No se trata simplemente de copiar a la naturaleza, sino de hacerlo como ella: sin generar residuos, de forma fácil y ahorrando energía. Se basa en tres principios fundamentales: la naturaleza como modelo, como medida y como mentor. Presenta un gran compromiso ecológico y es fundamental el rol de los ecosistemas ya que propone que el sistema socioeconómico los emule. Como bien afirmó el biólogo alemán Frederic Vester, citado por Pérez, "la naturaleza es la única empresa que nunca ha quebrado en 4000 millones de años". ${ }^{12}$

6) Economía Azul (Blue Economy): impulsada por Gunter Pauli, ${ }^{13}$ consideró que la denominada economía verde solo era para ricos y poco sostenible, a diferencia de la economía azul que se inspira en la tierra. Presenta puntos de contacto evidentes con los postulados del Cradle to Cradle y los fundamentos de la biomimesis. Se trata de

11 Adrián Rosemberg, "Ecología y simbiosis industrial: nuevos conceptos que agregan valor al relacionamiento productivo", Revista Virtual Pro. Ecología industrial (2008), acceso el 23 de junio de 2018, https:/www.revistavirtualpro.com/ revista/ecologia-industrial/4

12 Marina Pérez, "Biomimesis: cómo la naturaleza soluciona nuestros problemas", Fundación Melior (2012), acceso el 7 de mayo de 2018, http://www.fundacionmelior.org/content/tema/biomimesis-como-la-naturaleza-soluciona-nuestros-problemas

13 Este empresario y economista belga, anteriormente director ejecutivo de Ecover (una empresa ecológica pionera considerada modelo mundial), fue defensor durante 35 ańos de la economía verde. Se autodenomina el "Che Guevara de la sustentabilidad". 
un concepto holístico e innovador en el planteamiento empresarial, que emula los ecosistemas naturales para ser eficientes en la producción de bienes y servicios, con responsabilidad compartida y respeto para las generaciones futuras. En 1994 Pauli puso en marcha ZERI (siglas en inglés de Emissions Research and Initiatives, en español: Iniciativa e Investigación de Emisiones Cero), una red global para extender sus ideas. Desde entonces, ha creado 50000 empleos y más de 1500 empresas, con proyectos como el cultivo de hongos comestibles de alta calidad con desechos de café, detergentes biodegradables con restos de cáscaras de naranja o la transformación de gasolineras en estaciones de recarga para vehículos eléctricos. ${ }^{14}$

7 Capitalismo Natural (Natural Capitalism): el capitalismo es el uso productivo y la reinversión del capital; sin embargo, el capital comprende no solo dinero y bienes, sino también gente y naturaleza, que son aún más valiosas. Lovins profetiza que el capitalismo natural subsumirá al capitalismo industrial como el capitalismo industrial subsumió al agrarismo. El capitalismo natural es una propuesta de desarrollo empresarial y social impulsada por el Rocky Mountain Institute (RMI) de Estados Unidos y elaborada por los expertos Paul Hawken y Amory Lovins. Su tesis básica es que hay que pasar de la economía del consumo a la de los servicios y reinvertir los beneficios obtenidos en garantizar la conservación de los recursos naturales. Las propuestas básicas para avanzar hacia un nuevo desarrollo minimizando el dańo a los ecosistemas son: aumentar la productividad natural de los recursos reduciendo los desperdicios y el flujo destructivo de recursos, cambiar hacia modelos de producción inspirados en la naturaleza, avanzar hacia un modelo de negocio basado en las soluciones y no en los productos, impulsar un nuevo modelo socioeconómico que se sustente en el flujo de servicios y reinvertir en capital natural; el negocio debe reponer, sostener y expandir los ecosistemas del planeta. ${ }^{15}$

\section{Economía circular: concepto, principios y características}

En su prefacio a Nuestro futuro común, Gro Brundtland afirmaba que la exigencia de la Asamblea General de las Naciones Unidas sobre la creación de una "Comisión Mundial sobre el Medio Ambiente y el Desarrollo" significaba una clara demostración, por parte de la comunidad internacional, del sentimiento generalizado de frustración ante la ineficacia de responder a los temas centrales y decisivos mundiales. Han transcurrido tres décadas y este sentimiento de frustración expresado por la doctora Brundtland no ha mermado; es más, se

14 Este pensamiento se encuentra resumido en "Bienvenidos a la economía azul”, Ecointeligencia (2012), acceso el 15 de junio de 2018, https://www.ecointeligencia.com/2012/05/economia-azul-gunter-pauli/

15 Amory Lovins, Hunter Lovins y Paul Hawken, "La ruta hacia el capitalismo natural", Harvard Business Review, Reprint Number 99309 (1999), acceso el 9 de abril de 2018, https://www.terra.org/data/capitalismo_nat.pdf 
ha agudizado. Este documento se convirtió en el referente del concepto de desarrollo sostenible, entendiendo por tal el desarrollo que satisface las necesidades de la generación presente sin comprometer la habilidad de generaciones futuras de satisfacer sus propias necesidades. Para ello, el crecimiento no es suficiente, hay que mejorar la organización social y garantizar una distribución más equitativa de las rentas. La forma de concebir y percibir ese concepto ha cambiado mucho a lo largo de los años, generando dos interpretaciones predominantes: la teoría de las tres sostenibilidades (la más difundida) que lo considera un concepto integral abarcando, valga la redundancia, tres sostenibilidades (social, económica y ambiental) y la teoría de la desmaterialización del crecimiento o desacoplar el crecimiento de la base física, la que descansa, en buena medida, sobre la tecnología, en el desarrollo tecnológico como factor desmaterializador y una corriente emergente muy crítica de las anteriores: la del decrecimiento sostenible (a la cual nos referiremos más adelante). Resulta importante señalar que en la Cumbre para el Desarrollo Sostenible, celebrada en Nueva York, en 2015, se aprobó la Agenda 2030 para el Desarrollo Sostenible, incluyendo un conjunto de 17 Objetivos de Desarrollo Sostenible (ODS) y 169 metas adoptadas, que guiará las decisiones durante los próximos 15 años, conjugando las tres dimensiones del desarrollo sostenible.

Esta nueva economía tiene como su gran aliada a la tecnología informática y en especial a Internet, ya que permite la colaboración e intercambio de conocimiento más eficientes. Jeremy Rifkin en su libro La era del acceso afirmaba que durante la mayor parte de la era industrial se ponía el énfasis en la venta de bienes; en cambio, actualmente se produce un desplazamiento o transición desde un régimen de propiedad de bienes hacia un régimen de acceso. ${ }^{16}$ Las nuevas tecnologías de la información y la comunicación, como las aplicaciones móviles y los sistemas de información geográfica junto al incremento de las comunidades virtuales son algunos de los avances tecnológicos que posibilitan firmemente el surgimiento y el desarrollo de prácticas colaborativas. La economía "colaborativa" hace referencia a prácticas de compartir e intercambio que desacoplan la posesión de un producto de su uso y suelen implicar la utilización de menos recursos. ${ }^{17}$

En este escenario y recostándose en la desmaterialización producto de la tecnología, emerge la economía circular como una alternativa, que más que definirse dentro de un esquema cerrado, se puede conceptualizar como una filosofía del diseño ab initio, un sistema industrial restaurador o regenerativo inspirado en los seres vivos, que emula los ciclos de la naturaleza, en la que los "desechos" de una especie se convierten en el "alimento" de otra y así sucesivamente, distinguiendo entre ciclos técnicos y biológicos. En esta nueva economía, los recursos se regeneran dentro del ciclo biológico o se recuperan y restauran gracias al ciclo técnico.

16 Jeremy Rifkin, La era del acceso. La revolución de la nueva economía (España: Paidós, 2000), 5-7.

17 Programa de las Naciones Unidas para el Medio Ambiente, Descubriendo los caminos hacia una economía verde e inclusiva. Resumen ejecutivo (Ginebra: Programa de las Naciones Unidas para el Medio Ambiente, 2015), 22-24. 
Los componentes del ciclo biológico (nutrientes biológicos) son biodegradables, por lo que se pueden introducir en la naturaleza; en cambio, los del ciclo técnico (nutrientes técnicos como computadoras, motores, plásticos) son poco aptos para volver de inmediato a la misma, por lo que se diseñan para ser ensamblados y desmontados un gran número de veces, favoreciendo su reutilización una y otra vez retornándolo al sistema productivo. En definitiva, trata de desvincular el desarrollo económico global del consumo de recursos finitos. Presenta una perspectiva ambiciosa, desafiante y más atrevida que la economía verde puesto que requiere la transformación radical de los medios de producción, de las cadenas de suministro, de la cultura y de los hábitos de consumo a nivel planetario. ${ }^{18}$ La Comisión Europea, en el año 2014, en Comunicación al Parlamento hacia una economía circular: un programa de residuos cero para Europa, explica que una economía circular mantiene el valor añadido de los productos, materiales y recursos el mayor tiempo posible y reduce los residuos, reteniendo los recursos en la economía cuando un producto ha llegado al final de su vida para continuar utilizándose una y otra vez creando más valor. ${ }^{19}$

La economía circular se basa en tres principios claves, cada uno de los cuales aborda varios de los retos en términos de recursos y del sistema a los que han de hacer frente las economías industriales.

Principio 1: Preservar y mejorar el capital natural controlando reservas finitas y equilibrando los flujos de recursos renovables: de necesitarse recursos, el sistema circular busca que sean diseñados mediante un ciclo de desensamblado y reutilización y elige, en la medida de lo posible, tecnologías y procesos que utilizan recursos renovables o de mayor rendimiento. En esencia, busca que los productos sean diseńados y optimizados mediante un ciclo de desensamblado y reutilización. En este principio se identifican dos pilares: el ecodiseño y la economía funcional, a los que se añade la reducción del derroche. El diseño ecológico considera el impacto ambiental durante el diseño del producto. El Informe Técnico ISO/TR 14062:2002 (es) "Gestión ambiental - Integración de los aspectos ambientales en el diseño y desarrollo de productos" parte de la base que todos los productos, es decir, todos los bienes o servicios, tienen algún impacto sobre el ambiente en alguna o en todas las etapas de su ciclo de vida. ${ }^{20}$ En julio del 2011 se publicó la norma internacional ISO 14006:2011 "Directrices para la incorporación de ecodiseño", la primera norma internacional de gestión ambiental que integró aspectos propios del diseńo, la evaluación de los impactos en el ambiente de los productos

18 Ellen MacArthur Foundation, Hacia una economía circular. Resumen ejecutivo (Reino Unido: Ellen MacArthur Foundation, 2017), 5-7.

19 Comisión Europea, Comunicación de la Comisión al Parlamento Europeo. Hacia una economía circular: un programa de residuos cero para Europa. COM/2014/0398/FINAL (Bruselas: Comisión Europea, 2014).

20 ISO,Gestión ambiental - Integración de los aspectos ambientales en el diseño y desarrollo de productos. ISO/TR 14062:2002(es)” 2002, acceso el 21 de marzo de 2018, https://www.iso.org/obp/ui\#iso:std:iso:tr:14062:ed-1:v1:es. 
diseñados, y la gestión y tratamiento de dichos impactos dentro de una organización. ${ }^{21}$ Una vez que el objeto es producido y diseńado ecológicamente, se pasa al segundo principio que es lograr que su uso dure el mayor tiempo posible.

Principio 2: Optimizar los rendimientos de los recursos distribuyendo productos, componentes y materias con su utilidad máxima en todo momento, tanto en ciclos técnicos como biológicos: implica diseñar para refabricar, reacondicionar y reciclar — las tres $\mathrm{R}$ — para mantener los componentes técnicos y materias circulando. Los sistemas circulares utilizan bucles internos más estrechos (mantenimiento en lugar de reciclaje) preservando así más energía implícita. En el caso de los componentes técnicos, se diseñan desde su inicio para la reutilización, y los productos sujetos a rápidos avances tecnológicos se están diseñado para ser actualizados. El primer paso consiste en la reutilización (recuperar un producto a utilizar sin cambiar su forma o función). Pero puede ser que sea necesaria su reparación, es la renovación o la remanufactura, pero cuando no se puede usar, a veces es posible utilizar parte del mismo para crear otro objeto, entonces se trata de refabricación, llegando incluso al up-cycling, cuando el valor del objeto recién creado es mucho mayor que el valor del objeto original. Por último, se llega al final de la vida útil de un producto y para poder valorizar más todos los materiales que lo constituyen es necesario el reciclaje. ${ }^{22}$

Principio 3: Promover la eficacia de los sistemas detectando y eliminando del diseño los factores externos negativos. Incluye reducir los daños al uso humano, tales como los relacionados con los alimentos, la movilidad, la vivienda, la educación, la salud y el ocio. Además, la energía requerida para este ciclo debería ser renovable por naturaleza, para disminuir la dependencia a los recursos y aumentar la capacidad de recuperación del sistema (por ejemplo, frente a una crisis del petróleo).

Al comparar los principios de la economía circular con las escuelas de pensamiento enumeradas ut supra, se puede advertir que, por ejemplo, la filosofía cradle to cradle es totalmente circular, pero no a la inversa, vale decir, la economía circular es más abarcativa que cradle to cradle, coincidiendo ambas en los principios de refabricar, reacondicionar y reciclar, pero la economía circular incorpora todos los factores económico-sociales y se enfoca en el uso del producto y en las relaciones entre los fabricantes, proveedores y consumidores, tomando como pilar fundamental la desmaterialización a través de la tecnología. Tanto la biomimesis como la ecología industrial se centran en la forma de diseñar los productos, que emulen a los ecosistemas, uno de los principios de la economía circular. Para la biomimesis, al imitar las

21 ISO,Sistemas de Gestión ambiental — Directrices para la incorporación del ecodiseño. ISO 14006:2011(es). 2011, acceso el 21 de marzo de 2018, https://www.iso.org/obp/ui/\#iso:std:iso:14006:ed-1:v1:es

22 Benoit De Guillebon, "Los 7 Pilares de la Economía Circular". CEN Boletín de la Confederación de Empresarios de Navarra,Medio Ambiente(2014),4-5 
soluciones dadas por la naturaleza, subordina los sistemas económicos y sociales al entorno y no a la inversa, como el sistema económico lineal que subordina la naturaleza a los designios económicos. Es de destacar que en la ecología industrial la diversidad, pensar en sistemas, la proximidad y la cooperación son los pilares para crear una simbiosis industrial basada en los sistemas naturales. Entonces, el análisis de los flujos físicos de los recursos de la economía circular proviene de esta escuela. En cuanto a la economía azul, Pauli considera que la economía circular no es un cambio radical, es necesario un enfoque global del mundo y de todas las personas que lo habitan, los negocios necesitan una ética de la responsabilidad, no hay que salvar la economía sino la ética. En consecuencia, se centra en la ética, en la equidad social, en sostener los ecosistemas y la naturaleza y relega a segundo plano los intereses económicos. Por su parte, la economía del rendimiento le asigna un rol preponderante al reciclaje, pero la economía circular es más que reciclar, por tanto, es un marco, una noción genérica que recurre a varios enfoques específicos. Por último, el capitalismo natural presenta muchos puntos en común, resaltando la necesidad de reinvertir en capital natural, reponer, sostener y expandir los ecosistemas del planeta. La economía circular otorga la misma importancia a las tres dimensiones del desarrollo sostenible: social, económica y ambiental, ninguna prevalece por encima de las otras.

Una economía circular se define a partir de las siguientes características fundamentales: a) los residuos se eliminan del diseño (basura=alimento), b) la diversidad genera solidez y la energía necesaria para impulsar la economía circular debe ser de carácter renovable, para reducir la dependencia de los recursos e incrementar la resiliencia de los sistemas, c) pensar en sistemas: muchos elementos del mundo real, como empresas, personas o plantas, forman parte de sistemas complejos en los que las distintas partes están fuertemente vinculadas entre sí. En una economía circular, estos vínculos se tienen en cuenta en todo momento, d) los precios deben decir la verdad: los precios u otros mecanismos de retroalimentación deben reflejar los costes reales ya que los precios actúan como mensajes, y e) reemplazo del concepto de consumidor por el de usuario: la economía circular trae aparejada una nueva relación entre los consumidores y las cosas. Los consumidores acceden a los productos como usuarios, en lugar de apropiarse de ellos, como propietarios. Las compañías ofrecen como servicio sus productos que, una vez cumplida su función, son retirados por la empresa para volver a ser parte de un nuevo ciclo de producción. Por otro lado, las nuevas tecnologías de la información y la comunicación dan lugar a modelos de uso cooperativo o las redes de colaboración y uso compartido que generan más interacción entre los usuarios, vendedores y productores. A diferencia de la economía actual basada en 'comprar-y-consumir', los productos duraderos son arrendados, alquilados o compartidos siempre que sea posible.

El informe Intelligent Assets: Unlocking the Circular Economy Potential, elaborado por Ellen MacArthur Foundation en colaboración con World Economic Forum, pone el acento en la manera en que las innovaciones pueden ayudar a escalar la economía circular. Específicamen- 
te, Internet de las cosas (IoT, siglas en inglés de Internet of Things) juega un papel fundamental en la implantación de la economía circular. Sensores y dispositivos inteligentes conectados serán los encargados de hacer un seguimiento en tiempo real de los bienes para determinar su estado, el de sus componentes y calcular el valor de las materias primas que conservarán su utilidad más allá de la vida útil del producto acabado. ${ }^{23}$ Este impulso al Internet de las cosas no solo abarca el ámbito industrial y productivo, sino que la economía circular propone un nuevo modelo de sociedad más sostenible capaz de optimizar stocks y flujos de materiales en todas las actividades humanas. ${ }^{24}$

$\mathrm{Al}$ analizar este informe, se puede notar que un pilar fundamental de la economía circular lo constituye la desmaterialización del crecimiento, vale decir, desacoplar el crecimiento de la base física, lo que lleva a sus defensores a argumentar que es factible seguir creciendo sin comprometer los recursos naturales, en otras palabras, seguir creciendo y al mismo tiempo disminuir el consumo de recursos y los impactos ambientales.

Para la transición a una economía circular, las empresas pueden adoptar diferentes acciones: Regenerate (regenerar), Share (compartir), Optimise (optimizar), Loop (bucle), Virtualise (virtualizar) y Exchange (intercambiar), que juntas conforman el marco ReSOLVE (por las siglas de las iniciales de las palabras inglesas).

\section{Luces y sombras de la economía circular}

La mayor barrera es la dificultad de romper hábitos arraigados de los fabricantes, de la cadena de suministros y de los consumidores y usuarios. Según el informe del grupo de trabajo del Programa de Naciones Unidas para el Medio Ambiente, los principales problemas que entraña el desacoplamiento son: explicar cómo el conocimiento de los flujos de recursos mundiales puede integrarse con los retos relacionados; convencer a los decisores políticos (y al público) que los límites físicos reales de los recursos naturales no renovables llaman a la acción; acelerar el desacoplamiento ya iniciado entre el consumo de recursos y la economía; desarrollar señales de mercado adecuadas; promover las ciudades como espacios privilegiados para concretar en la práctica el concepto de desacoplamiento de los modos de producción y consumo y demostrar que el desacoplamiento es un requisito previo indispensable para reducir los niveles mundiales de desigualdad social. ${ }^{25}$

23 Ellen MacArthur Foundation y World Economic Forum, Intelligent Assets: Unlocking the Circular Economy Potential (Reino Unido: Ellen MacArthur Foundation, 2016),13-15, 24-25.

24 Es el caso de la denominada ciudad circular o ciudad inteligente (smart city), que se caracteriza por un mejor aprovechamiento de los recursos y un cambio en la experiencia de sus ciudadanos.

25 Programa de Naciones Unidas para el Medio Ambiente, Extracto del informe desacoplar el uso de los recursos naturales y los impactos ambientales del crecimiento económico(2011), acceso el 21 de mayo de 2018, https://www.zaragoza.es/contenidos/medioambiente/onu/349-spa-sum.pdf 
Pero quizás las más importantes y difíciles de rebatir son las basadas en las leyes de la termodinámica y la denominada "paradoja de Jevons". En efecto, afirman sus detractores, que bajo la ilusión de la economía circular parecería que el crecimiento puede continuar de manera ilimitada, pues se estarían reciclando los residuos y convirtiéndolos en nuevos recursos, bajo el eslogan zero waste (residuo cero). El problema, señalan, es que en este planteamiento hay dos errores fundamentales. El primero es que no tiene en cuenta las leyes básicas de la física, como la Segunda Ley de la Termodinámica, consistente en que todo proceso implica un consumo de energía. Entonces el propio proceso de reciclaje de recursos implica, por un lado, una pérdida de recursos, pues el reciclaje no es posible al $100 \%$, y por otro, un gasto energético en el propio proceso de reciclado.

El segundo error reside en que tampoco reparan en la paradoja de Jevons, conforme la cual las mejoras en la eficiencia de uso de un recurso no siempre llevan a un menor uso del recurso, sino que pueden derivar, por el contrario, en un uso mayor. La paradoja de Jevons, denominada así por su descubridor — William Stanley Jevons_-, afirma que a medida que el perfeccionamiento tecnológico aumenta la eficiencia con la que se usa un recurso, lo más probable es que aumente el consumo de dicho recurso, antes que disminuya. Concretamente implica que la introducción de tecnologías con mayor eficiencia tecnológica puede, a la postre, aumentar el consumo total de energía. A esta contradicción también se la denomina "efecto rebote". ${ }^{26}$ Por otra parte, en ámbitos científicos hablan de la "cuadratura del círculo" de la economía circular en cuanto al reciclaje de materiales. El uso de los materiales por año se divide en las siguientes categorías: doce gigatoneladas — GT — de combustibles fósiles (petróleo, gas, carbón) que en casi su totalidad van para ser quemados en la producción de electricidad, consumo doméstico, o en el transporte; diecinueve gigatoneladas - GT — de biomasa para muchos usos distintos, la alimentación del ganado o directamente la alimentación humana, la producción de pasta de papel, de madera para construcción, y la mayor parte de madera para quemar; veintidós gigatoneladas — GT — de materiales de construcción, arenas y gravas para cementos, y por último, el cuarto sumando, a nivel mundial, es 4,5 gigatoneladas — GT — de materiales metalíferos, ingresando en la economía en promedio menos de una gigatonelada — GT - de metales ya concentrados y refinados, algunos de más fácil reciclaje que otros. En consecuencia, varios científicos llegaron a la conclusión de que, en conjunto, lo que se recicla actualmente en el mundo no es más de $6 \%$ de los materiales extraídos, lo que ocasiona un alejamiento de la posibilidad de lograr una economía circular ${ }^{27}$.

El exministro de Ambiente, Alimentación y Asuntos Rurales del Reino Unido, Dan Rogerson, recibió muchas críticas al declarar que una economía completamente circular no era

26 Jesús Ramos Martín, “Economía Biofísica”, Investigación y Ciencia (2012).

27 Willi Haas et al, "How Circular is the Global Economy? An Assessment of Material Flows, Waste Production,and Recycling in the European Union and the World in 2005",Journal of Industrial Ecology (2015) 
ni factible ni deseable porque llegaba un punto en el que el costo de tratar de recuperar los materiales con el reciclaje superaría los beneficios de hacerlo, ya sea en términos de uso de energía, de emisiones de dióxido de carbono, otros daños ambientales, y/o dinero. No todos los productos se pueden reutilizar, desmantelar y refabricar sin ningún tipo de generación de residuos, y sin requerir el uso de las materias primas vírgenes adicionales. Finalmente, este político hace notar que las recientes propuestas de la Comisión Europea sobre la economía circular apuntan a una tasa de reciclado del $70 \%$, calificándose, con razón, como "ambiciosas". Evidentemente, concluye que, de acá a 2030, la Comisión no cree que sea posible reciclar todos los residuos. ${ }^{28}$

Para muchos economistas resulta imposible pensar en un desarrollo económico basado en el continuo aumento en la producción de bienes que también esté en armonía con la sostenibilidad del ambiente, lo que dio origen a la "teoría del decrecimiento". En ella confluyen dos áreas principales: la primera, la bioeconomía, parte del análisis de los factores termodinámicos y biológicos del proceso económico, desarrollado originalmente por el matemático y economista rumano Nicholas Georgescu-Roegen en los setenta, quien, entre otras cosas, distinguió entre alta entropía (energía no disponible para la humanidad) y baja entropía (energía disponible), haciendo hincapié en los límites que las leyes de la naturaleza le imponen al crecimiento económico y situando a la economía como un subsistema de la biosfera. Y la segunda parte de la falta de las políticas de desarrollo en el Sur, con el apoyo en los últimos ańos principalmente de Serge Latouche. Los teóricos del decrecimiento no admiten ningún intento de conciliar el crecimiento y la protección del ambiente, y critican sobre todo el término desarrollo sostenible ya que consideran que es un concepto vacío que encierra una contradicción porque la empresa moderna ya no es sostenible. Para este autor, el decrecimiento no es un concepto, es un simple eslogan mediático creado para escandalizar, para crear impacto ya que nadie hace nada para intentar resolver la problemática, los políticos hablan de reducir los niveles de contaminación, pero luego dictan leyes que permiten el uso indiscriminado de pesticidas, deforestaciones, o generan la guerra del petróleo. En su libro La apuesta por el decrecimiento, explica que dicha teoría es un proyecto político consistente en la construcción, tanto en el Norte como en el Sur, de sociedades convivenciales autónomas y ahorrativas. El cambio radical proviene de lo que denomina los pilares del decrecimiento o el modelo de las "8 R": revaluar: significa sustituir los valores globales, individualistas y consumistas por valores locales, de cooperación y humanistas; reconceptualizar: parte de la base que la economía considera a la naturaleza como una mercancía y se debe realizar un cambio de valores, la naturaleza por encima de la economía presentando una visión biocéntrica, a diferencia de las visiones antropocéntricas que someten la naturaleza a los designios de la economía; reestructurar:

28 Roy Hathaway, “¿Es la economía circular alcanzable o deseable?”, Economía circular y minería urbana. (2014), acceso el 30 de abril de 2018, https://mineriaurbana.org/2014/08/12/es-la-economia-circular-alcanzable-o-deseable/ 
es necesario adaptar el aparato de producción y las relaciones sociales en función de la nueva escala de valores: menos no es peor, menos es más; relocalizar: equivale a producir localmente, fomentar las economías regionales; redistribuir: tiene un doble efecto positivo, por un lado, de forma directa, reduciendo el poder de la clase consumidora mundial (el Norte tiene una deuda con el Sur), y por otro, de manera indirecta, disminuyendo el consumo desmedido; reducir: vale decir, disminuir el impacto en la biosfera de la manera de producir y consumir, las horas de trabajo, el consumo sanitario y el turismo de masas y reutilizar y reciclar: alargar el tiempo de vida de los productos para evitar el consumo y el despilfarro. ${ }^{29}$ Es importante destacar el cambio de cosmovisión presente en esta teoría, de la antropocéntrica predominante en la actualidad, a la biocéntrica. Sin embargo, el término decrecimiento no es fácilmente aceptado, surgiendo críticas por sus connotaciones negativas, por ejemplo, ocasionaría un gran desempleo y porque parece contradictorio que ahora se plantee decrecer también a los países en los que la mayoría de la población no ha llegado a conocer ni los mínimos derechos básicos, tales como alimentación, agua potable, vivienda digna, y que los habitantes de los países desarrollados del Norte (y las elites privilegiadas del Sur) no tengan derecho para exigir a los países del Sur que decrezcan. ${ }^{30}$

Pero volviendo a la economía circular y frente a las críticas detalladas anteriormente, también se escuchan voces en su defensa ya que estiman que este tipo de economía redundaría en beneficios ambientales, sociales y económicos. En cuanto a los ambientales, señalan que los recursos naturales (energía, agua y materias primas) se utilizan repetidamente, conservándose dentro de la economía local el mayor tiempo posible y reduciéndose la extracción de materias primas. La mayor productividad del suelo, la reducción de residuos en la cadena de valor de la alimentación y la vuelta de los nutrientes al suelo incrementará el valor de la tierra y del suelo como activos, a la vez que reduciría la necesidad de reposición con nutrientes adicionales. En lo referido a los beneficios económicos, la transición hacia una economía circular generará grandes oportunidades para empresas innovadoras y otorgará una ventaja competitiva a quienes sean capaces de anticiparse a la demanda en los mercados de servicios de ingeniería y ecología industrial. ${ }^{31}$ La alianza entre la economía circular y la tecnología es capaz de cambiar drásticamente la industria en pocos años, acelerando la transición desde un modelo lineal de producción masiva y obsolescencia programada, a uno cerrado, circular, bajo demanda (on-demand) que produce solo lo imprescindible, justo donde y cuando se necesita. Las consecuencias para los países son enormes, puesto que se volvería a regionalizar sectores industriales enteros, reduciendo la vulnerabilidad de las

29 Serge Latouche, La apuesta por el decrecimiento: ¿cómo salir del imaginario dominante? (Barcelona: Icaria Editorial, 2008).

30 Pepa Grisbert Aguiar, "El decrecimiento, camino hacia la sostenibilidad", El Ecologista (2007).

31 Carlos Martínez Camarero, "Más allá del reciclaje, avanzar hacia la producción limpia, el ecodiseño y los biomateriales", Daphia (2016), acceso el 15 de mayo de 2018, http://www.daphnia.es/revista/64/articulo/1258/Mas-alla-del-reciclaje-avanzar-hacia-la-produccion-limpia-el-ecodisenyo-y-los-biomateriales. 
actuales —e inestables_— cadenas de suministro, creando empleo local y asegurando ciclos de producción y consumo más eficiente. ${ }^{32}$ Y entre los sociales se destaca el valor del trabajo, el capital y la tecnología invertida. La capacidad de generación de empleo de la economía circular está por encima de la que ofrece una gestión de residuos basada en el vertido, la incineración e incluso el reciclaje.

Si bien, en la actualidad, una economía totalmente circular todavía no es alcanzable, esto no significa que no se pueda avanzar en las áreas en las cuales se pueda reutilizar y reciclar. Justamente, todas estas diferentes líneas de pensamiento coinciden en la necesidad de modificar el sistema de producción actual, concibiendo los productos para refabricar, reacondicionar, reciclar y desvincular la economía de los combustibles fósiles, altamente contaminantes, utilizando, en su lugar las energías renovables.

\section{AVANCES: PRÁCTICAS EMPRESARIALES ARGENTINAS}

Entre las empresas argentinas hay una tendencia creciente a incorporarse al circuito circular. En algunos casos lo hacen con mayor familiaridad porque se trata de multinacionales cuyas filiales locales trabajan en sintonía con sus casas matrices radicadas en países que están mucho más avanzados en la experiencia. En otros, porque está cada vez más aceptado que la sustentabilidad permite obtener mejores resultados, tanto en la optimización de recursos como en la rentabilidad.

El 11 de noviembre del 2017 se llevó a cabo la presentación del Programa de la Fundación Ellen MacArthur para la Economía Circular, organizada de manera conjunta por la red mundial de parlamentarios Globe International, la oficina para el Cono Sur de ONU Medio Ambiente y la Dirección General de Relaciones Internacionales de la Cámara de Diputados de la Nación argentina, con el objeto de avanzar en una agenda conjunta que incluya la Economía Circular para 2030. La presentación estuvo a cargo de la líder del Programa de Gobiernos y Ciudades de la Fundación Ellen MacArthur, ${ }^{33}$ y durante la jornada se abordó el tema en el marco de la Agenda 2030 sobre Desarrollo Sostenible. Luego de la presentación, se acordó continuar debatiendo las estrategias y herramientas para la implementación de políticas hacia la economía circular. ${ }^{34}$

Durante 2017, el Centro de Reciclado de E-Basura de la Universidad Nacional de La Plata envió, junto con la Provincia de Buenos Aires, a deposición final 14,20 toneladas de material informático. En tanto 16200 personas pertenecientes a unas 40 entidades educativas, ins-

32 Nicola Cerantola, "Reflexiones sobre el pasado, presente y futuro de la economía circular", Revista Ambienta (2016).

33 Su función se centra en otorgar apoyo al sector público, tanto a nivel nacional como regional y municipal, para establecer condiciones para la transición a una economía circular.

34 Carolina Diotti, Jornada sobre economía circular y objetivos de desarrollo sostenible 2030 (Los verdes, 2017), acceso el 28 de junio de 2018, http://www.losverdes.org.ar/jornada-economia-circular-objetivos-desarrollo-sostenible-2030/ 
tituciones y organizaciones no gubernamentales de La Plata, Gran La Plata y el Conurbano fueron beneficiadas con la entrega de elementos informáticos reciclados por los propios integrantes del programa. En el predio se dictaron en el año 12 cursos de formación en forma gratuita que alcanzó a un centenar de alumnos.

\section{Desperdicio de alimentos}

Por "desperdicio de alimentos" se entiende las pérdidas derivadas de la decisión de desechar alimentos que aún tienen valor, lo que se asocia principalmente con el comportamiento de los vendedores mayoristas y minoristas, los proveedores de servicios de venta de comida y los consumidores. De acuerdo con un estudio elaborado, en el año 2012, por la Organización de las Naciones Unidas para la Alimentación y la Agricultura (FAO) intitulado, "Pérdidas y desperdicio de alimentos en el mundo", 35 un tercio de los alimentos producidos mundialmente para el consumo humano se pierde o se desperdicia, lo que equivale a cerca de 1300 millones de toneladas al ańo. Los alimentos se pierden o se desperdician a lo largo de toda la cadena de suministro, desde la producción agrícola inicial hasta el consumo final en los hogares. Estas pérdidas representan un desperdicio de los recursos e insumos utilizados en la producción, como tierra, agua y energía, incrementando inútilmente las emisiones de gases de efecto invernadero. El Instituto Nacional de Tecnología Agropecuaria (INTA), en el marco del Proyecto Específico Tecnologías de Preservación de Alimentos y Aprovechamiento de Subproducto del Programa Nacional de Agroindustria y Agregado de Valor, ${ }^{36}$ busca desarrollar, adaptar y transferir tecnologías que permitan dar respuesta a problemas concretos relacionados con tecnologías de preservación de alimentos y aprovechamiento de subproductos.

Durante el año 2017, la FAO elaboró un "Informe final diseño metodológico para la estimación de los desperdicios de alimentos de la Argentina en las etapas de distribución y comercio minorista, y consumo en el hogar", producido por el Centro de Investigaciones sobre Desarrollo Económico, Territorio e Instituciones (CIDETI), Alma Mater Studiorum - Università di Bologna, Representación en la República Argentina. Los resultados preliminares del informe tomaron como referencia las estimaciones realizadas en Italia o Francia, por lo cual concluyeron que el fenómeno total de las pérdidas y desperdicios de alimentos en Argentina, en sus varias fases, podría alcanzar el 2,5\% del PBI, es decir, aproximadamente 11 875 millones de dólares. Considerando, por otra parte, que el país tiene un nivel de organización para la producción y consumo de alimentos intermedia entre los países desarrollados y los países en vías de desarrollo, los desperdicios alimenticios (es decir, aquel fenómeno que

35 Organización de las Naciones Unidas para la Alimentación y la Agricultura, Pérdidas y desperdicio de alimentos en el mundo - Alcance, causas y prevención (Roma: FAO, 2012), 2-10.

36 Dicho Proyecto puede ser consultado en la página web del INTA: Instituto Nacional de Tecnología Agropecuaria, Proyecto Específico Tecnologías de Preservación de Alimentos y Aprovechamiento de Subproducto del Programa Nacional de Agroindustria y Agregado de Valor, acceso el 20 de febrero de 2018, https://inta.gob.ar/proyectos/PNAIyAV-1130033 
se produce solo en la fase de distribución y consumo) podrían alcanzar una cifra cercana a los 5000 millones de dólares anuales, es decir, un costo absolutamente relevante. No obstante, alerta que son estimaciones totalmente preliminares, a la espera de cálculos bien realizados localmente, y solo con la intención de ilustrar cuál podría ser la magnitud bajo estudio y la necesidad de realizar con urgencia estimaciones científicamente controladas, más que nada por las dificultades en la recolección de los datos por parte de los pequeńos supermercados. Las grandes cadenas internacionales de autoservicios desarrollan procedimientos informatizados para detectar lo que en el lenguaje de las cadenas de supermercados se denomina "merma", es decir, toda diferencia de inventario entre la mercadería comprada y la mercadería vendida, por lo cual queda perfectamente registrado el desperdicio de alimentos por rubro y por causa. En este caso, donde la información sobre desperdicios está perfectamente disponible en los registros contables/administrativos, el desafío consiste en obtener la colaboración de las más altas autoridades de la propiedad. Por el contrario, se registró un alto nivel de resistencia a brindar colaboración para esta investigación por parte de los autoservicios chinos y pequeños supermercados independientes, compuestos por empresas pequeñas y medianas. ${ }^{37}$

Mientras que los alimentos se desperdician, con ellos se podría alimentar tres veces a las personas desnutridas, además que las previsiones mundiales sugieren que la producción de estos se debe duplicar para poder abastecer la creciente demanda de una población en aumento. En Argentina, el problema de la malnutrición afecta a 2 millones de personas aproximadamente con mayor severidad a nińos y adultos mayores. El Observatorio de la Deuda Social de la Universidad Católica Argentina señala que 2 de cada 10 chicos del país no acceden a una alimentación adecuada y la mitad padece "inseguridad alimentaria severa", lo cual significa que sufren hambre por causas económicas. ${ }^{38}$

Frente a tal contradicción, varias ONG se unieron al proyecto Nilus, que es una organización sin fines de lucro que conecta, a través de su plataforma de financiamiento colectivo, a empresas con excedentes de alimentos con comedores sociales, facilitando el transporte de esos alimentos a través de una comunidad de choferes particulares. Utiliza la tecnología de crowd sourcing ${ }^{39}$ y geolocalización para conectar donantes de alimentos, comedores sociales y

37 Organización de las Naciones Unidas para la Alimentación y la Agricultura, Informe final diseño metodológico para la estimación de los desperdicios de alimentos de la Argentina en las etapas de distribución y comercio minorista, y consumo en el hogar (Buenos Aires: Organización de las Naciones Unidas para la Alimentación y la Agricultura, 2017), 112-114.

38 Mariana Valls, “¿Cuánto ambiente desperdiciamos para producir los alimentos que no se consumen? ¿Es realmente necesario duplicar la producción de alimentos para satisfacer las necesidades de nuestra población creciente?”, El Dial. com Biblioteca Jurídica Online (2017). elDial DC23CA.

39 El crowd sourcing surgió como una forma de tercerizar trabajos, pero ha evolucionado y ya es un modelo de negocios sobre el cual reposan muchas empresas. La palabra es reciente y fue creada por Jeff Howe. Etimológicamente, proviene de crowd (multitud) y sourcing (abastecimiento), vale decir que consiste en utilizar la fuerza de las multitudes como proveedoras de trabajo, generalmente intelectual. El ejemplo más famoso de crowd sourcing es Wikipedia, una enciclopedia virtual escrita y actualizada permanentemente por sus lectores. 
choferes particulares, de una forma sencilla e intuitiva. Un donante notifica la disponibilidad de comida, el comedor social accede a la notificación y solicita la donación, los choferes Nilus reciben el pedido de viaje y uno lo acepta y, finalmente, la comida que iba a ser desperdiciada termina alimentando a quien más lo necesita. En su sitio web explican los poderosos motivos que impulsan generar este mecanismo: el $40 \%$ de la comida que se produce en el mundo se tira, 1,3 millones de toneladas de comida desperdiciada por año, 850 millones de personas que sufren hambre, 3,3 gigatones de gases de efecto invernadero lanzados a la atmósfera. El modelo es autosustentable: se cobra a los comedores una suma casi simbólica, de entre cinco y diez pesos por kilogramo de comida, para solventar los costos de logística y operación, al igual que hacen los Bancos de Alimentos. Cuenta con una prueba piloto en el Banco de Alimentos de Rosario, provincia de Santa Fe, y en la Argentina genera 16 millones de toneladas de desperdicios al año, es decir, 1 kilo de comida por día. Este proyecto argentino fue uno de los finalistas del Desafío Google.org que busca fomentar proyectos de innovación con impacto social. ${ }^{40}$

\section{Las empresas $B$}

El día 23 de junio de 2016, Cervecería y Maltería Quilmes desarrolló el "Primer Encuentro Nacional sobre Economía Circular: Retorna a la Tierra: Diálogos sobre el Medio Ambiente", donde se reunieron especialistas de distintos sectores e industrias para presentar sus prácticas sustentables y abordar los ejes de la Economía Circular aplicada a los negocios. Asimismo, el 4 de octubre de 2016, se desarrolló en el Anexo del Senado de la Provincia de Buenos Aires el "Primer Encuentro Provincial de Responsabilidad Empresaria y Reciclaje", donde se debatió la problemática de los residuos y se sentaron las bases para la consolidación de un modelo de economía circular. ${ }^{41}$ A tales efectos, es importante analizar si estos emprendimientos privados se comprometen o no con la economía circular ya que existen muchas empresas que se autopromocionan como sostenibles y responsables con el ambiente, debido más que nada a la exigencia de los consumidores al adquirir sus productos y por razones de marketing verde (lo verde, vende), pero en realidad siguen siendo igual de contaminantes. A esta práctica empresarial se la conoce como green washing, la cual presenta diferentes grados y técnicas, que van desde mentir y engañar hasta simplemente ser sostenible en algunos aspectos y no en otros, pero la más habitual es la que consiste en utilizar términos como eco, ecológico, orgánico, bio, y emplear envases plásticos de color verde. Tan es así que, en 2004, la Comisión Europea aprobó el Reglamento N ${ }^{\circ} 392 / 2004$, reservando la utilización de los términos eco, ecológico, biológico u orgánico y sus diminutivos solamente para los productos procedentes de la agricultura ecológica. Anteriormente, en Argentina, el Decreto Nacional

40 Para mayor información se puede consultar su página web: Nilus, Tecnología al rescate de los alimentos, acceso el 22 de julio de 2018, https://www.nilus.org/

41 Provincia de Buenos Aires. Organismo Provincial para el Desarrollo Sostenible, La provincia dio el primer paso hacia una economía circular (2016), acceso el 13 de mayo de 2018, http://wwwa.opds.gba.gov.ar/index.php/articulos/ver/1243 
N 206-2001 se expidió en igual sentido. En el 2012, la ONG World Wildlife Fund publicó el Report Green - Game Changes identificando las 10 empresas en el mundo que a su entender habían implementado verdaderas medidas sostenibles ${ }^{42} \mathrm{y}$ en igual sentido los premios The Circulars. ${ }^{43}$

Entre las empresas argentinas que llevan adelante iniciativas sustentables podemos mencionar:

a) Cervecería y Maltería Quilmes: en este programa, el consumidor retornaba el envase y la marca se comprometía a mantener el precio de su nuevo porrón de $340 \mathrm{~cm}^{3}$ retornable a 10 pesos hasta fin del año 2016. La marca tuvo como objetivo generar el hábito positivo en la sociedad y concientizar sobre la importancia de utilizar envases retornables, que permiten cuidar el planeta. Las botellas retornables son producidas a partir de vidrio reciclado, un material que es reusado 29 veces en promedio y además es $100 \%$ reciclable. El sistema retornable propone reemplazar el ciclo de "usar y tirar" por el de "usar, reutilizar y reciclar". La reutilización permite el uso eficiente de los recursos y es una industria de industrias que genera 91200 puestos de trabajo en todo el país. Aproximadamente 9 de cada 10 envases de Quilmes son retornables; así, cada 1000 litros de cerveza, se necesitan solamente 34 botellas retornables de 1 litro, vale decir que, al ser reutilizables, se utilizan 966 botellas menos. Por cada 1000 litros de cerveza consumida en envases retornables, se evita el equivalente a la cantidad de residuos domiciliarios que generarían 460 personas por día, según datos de Residuos Sólidos Urbanos. Si el envase de vidrio es reutilizado 29 veces, la reducción del dióxido de carbono equivale a las emisiones de un viaje en auto de 1900 kilómetros. ${ }^{44}$

b) Rigolleau S. A.: la industria del vidrio fue una de las primeras en utilizar en forma continua un alto porcentaje de vidrio reciclado, y en el caso particular de Rigolleau, casi el $50 \%$ de la materia prima proviene de envases recuperados.

c) Trocafone, IBM y Brightstar Fueguina: como hay un mercado de autos usados, también existe, en Argentina, el mercado de los celulares usados, a través de un proceso conocido como refurbish (refabricado), que consiste en tomar un teléfono con determinados defectos, repararlo y devolverlo al mercado. Trocafone, empresa creada a

42 La lista de empresas se encuentra disponible en: World Wildlife Fund, Report Green-GameChanges (Reino Unido: WWF, 2012).

43 El Foro Económico Mundial y el Foro de Jóvenes Líderes Globales, en colaboración con Accenture Strategy, crearon The Circulars - Premios a la Economía Circular-, con el objetivo de reconocer las contribuciones de los Gobiernos, las multinacionales y las pymes en la adopción de los principios de la economía circular.

44 Para mayor información véase: "La cerveza retornable, nuestra primera economía Circular", La Nación, 5 de jun. de 2016, sección Economía, acceso el 5 de julio de 2018, http://www.lanacion.com.ar/1905480-la-cerveza-retornable-nuestra-primera-economia-circular 
fines de 2014, detectó que había un potencial muy grande en el mercado secundario de smartphones, que en la Argentina se estima que representa entre $5 \%$ y $7 \%$ del mercado de nuevos (entre 500000 y 700000 unidades por ańo), mientras que en plazas más maduras representa entre el 10 y el $15 \%$. Trocafone acordó con Movistar que le maneje el "plan canje", y el celular usado, entregado en Movistar, es recogido por Trocafone que lo lleva a su laboratorio, donde los técnicos procesan los teléfonos (chequean 30 puntos de verificación). Entonces, hay dos posibilidades: que funcione bien, en cuyo caso se limpia, se hace un upgrade del software y se lo destina a la venta, o que tenga algún inconveniente, en cuyo caso se lo repara y posteriormente se lo pone a la venta. También Brightstar Fueguina es otra de las empresas que refabrican celulares y lanzó su servicio para uno de sus principales clientes: Samsung. Y desde el 2015, BGH Logistic Services compró casi 100000 equipos de todas las marcas y tipos para reacondicionarlos y venderlos. Para ello desarrolló una plataforma informática donde los retailers o agentes de servicio técnico ingresan el modelo del equipo y automáticamente ven reflejado el precio que le deben ofrecer al cliente. Según estiman en BGH, estos equipos refabricados vuelven al mercado con un valor que se ubica entre el $65 \%$ y el $75 \%$ del precio de uno nuevo. ${ }^{45}$

d) Xinca: es una marca de zapatillas confeccionadas por internos de un penal a partir de residuos. Solo en Argentina se desechan 100000 toneladas de neumáticos al año, por tanto, esta empresa, instalada en la provincia de Mendoza, busca recuperar un buen porcentaje de ese caucho - tras un proceso de triturado - para confeccionar las suelas del calzado. De la industria textil y sus rezagos — otro gran agente contaminador - toman parte del material para las capelladas. Ya llevan recicladas 13 toneladas de neumáticos y casi dos toneladas de rezagos textiles. Gracias a ello llevan confeccionados 20000 pares desde sus comienzos, lo que significa que reciclaron más de 13 toneladas de neumáticos, dos toneladas de bladder (residuo de la construcción de neumáticos) y casi dos toneladas de residuos textiles. Además, y no menos importante, lograron que actualmente en el taller trabajen 32 internos del penal de San Felipe, ubicado en la citada provincia. La mayor parte de la venta se realiza online a través de la propia página de Xinca y por Mercado Libre. ${ }^{46}$

e) Café Martínez relanzó durante el año 2016 su plan nacional de reciclaje con sus dos acciones de responsabilidad social empresarial a nivel nacional: por un lado, continúa con la segunda etapa de su campaña de recolección de cápsulas biodegradables de café

45 Estos datos se pueden consultar en Carlos Manzoni, "Los celulares 'refabricados' ganan mercado en el país", $\mathrm{La} \mathrm{Na-}$ ción, 22 de oct. de 2017, sección Economía/Negocios, acceso el 29 de junio de 2018, http://www.lanacion.com. ar/2074235-los-celulares-refabricados-ganan-mercado-en-el-pais

46 Meri Castro, "Las zapatillas ecológicas confeccionadas por presos", La Nación. Revista Brando (10 de oct. de 2017), acceso el 20 de julio de 2018, http://www.lanacion.com.ar/2070893-las-zapatillas-ecologicas-confeccionadas-por-presos 
express a beneficio de la Fundación Garrahan (por cada 50 cápsulas limpias, vacías para reciclar, cada cliente se llevaba una caja nueva con 10 cápsulas blend de café que desearan) y, en simultáneo, proveerá de papel y cascarillas de café a la Fundación Steps con el objeto de potenciar las capacidades sociales e intelectuales de las personas con discapacidad. La marca proporcionó papel y cascarillas de café, para ser reutilizados por los integrantes de la institución para la fabricación de posavasos y otros elementos que luego fueron entregados a los clientes de la marca.

f) Sirplast: comenzó su actividad en agosto del año 2013, en la localidad de Munro, provincia de Buenos Aires, donde recibe y recicla exclusivamente poliestireno expandido, comúnmente conocido como telgopor (por ejemplo, vasos descartables, bandejitas de comida, potes de helado y embalajes). Cada mes recicla un volumen de 65 camiones con acoplado (que antes enterraba en el CEAMSE) para convertirlo en materia prima plástica. ${ }^{47}$

g) Fundación Eco Inclusión: es una fundación de la provincia de Córdoba que fabrica ladrillos ecológicos a partir del reciclaje de botellas de plástico, que ganó, el 16 de noviembre de 2017 en México, la final regional del desafío Google.org, que estimula desarrollos que impactan de forma positiva en la sociedad. La iniciativa de la ONG argentina se basa en triturar el plástico de 20 botellas para lograr un ladrillo que tiene las mismas medidas y capacidades constructivas que uno de barro cocido tradicional, pero es más liviano, más aislante, no daña el ambiente y soluciona el problema de la basura. La fundación tiene tres plantas de producción y todo el desarrollo previo fue realizado con el apoyo técnico-científico del Consejo Nacional de Investigaciones Científicas y Técnicas (Conicet) y de la Secretaría de Vivienda y Hábitat de la Nación, que lo habilita para la construcción de viviendas. En la Argentina se desechan 12 millones de botellas plásticas por día, de las que se recicla solo el $15 \%$, y 3 millones de argentinos carecen de vivienda digna. Los ladrillos ecológicos fabricados con botellas plásticas permitirán reciclar más de 50000 toneladas de plástico por año, que servirán para construir casi un millón de metros cuadrados de viviendas sustentables. El objetivo consiste en crear 4120000 ladrillos por mes, permitiendo la producción de 50 millones de ladrillos ecológicos por año, para construir más de $830000 \mathrm{~m}^{2}$ de viviendas sustentables. Con construcciones ecológicas de $30 \mathrm{~m}^{2}$, se ayudará a 27500 familias de bajos recursos por año, eso sin sumar el beneficio del reciclado de 8240000 botellas plásticas por mes, el equivalente al $28 \%$ del plástico que actualmente se desecha en el país. ${ }^{48}$

47 Florencia Tuchín, "Hacia una economía circular”, El Cronista, 20 de oct. de 2016, acceso el 10 de febrero de 2018, http:// www.cronista.com/responsabilidad/Hacia-una-economia-circular-20161020-0024.html

48 "Argentinos que fabrican ladrillos con botellas recicladas y ganaron un premio de Google", La Nación, 16 de nov. de 2017, sección Sociedad/Ecología, acceso el 10 de julio de 2018, http://www.lanacion.com.ar/2082927-argentinos-que-fabrican-ladrillos-con-botellas-recicladas-y-ganaron-un-premio-de-google 
h) Ball Corporationes, el mayor productor de latas de aluminio en Argentina, cuenta con programas para el cuidado del ambiente y una gestión sustentable de su proceso productivo. Las latas de aluminio son $100 \%$ reciclables y la estrategia global de esta empresa, de cara al 2020, consiste en reducir la huella de carbono en un $25 \%$. En cinco ańos de trabajo logró reducir más del $15 \%$ de todo su consumo de energía en América del Sur. El uso eficiente del agua también está en su agenda, y entre enero y junio del año 2017 ya ahorró en Sudamérica más de 6 millones de litros de agua. ${ }^{49}$

i) DAK Americas: en el año 2014 la compañía comenzó a desarrollar, en su planta industrial ubicada en Pacheco, provincia de Buenos Aires, operaciones de recolección y reciclado de botellas PET, PET reciclado (rPET) para uso alimentario. Actualmente se utilizan alrededor de 200000 t/ańo y solo se recupera alrededor del $25 \%$, es decir, 50000 t. El resto va a parar a basurales, ríos, arroyos y cunetas. La capacidad máxima de la planta Ecopek es de 12000 toneladas/año, y por cada tonelada que se recicla, se ahorran 3,8 barriles de petróleo, $75 \%$ de energía gases de efecto invernadero y $5,7 \mathrm{~m}^{3}$ de relleno sanitario o basural. ${ }^{50}$

j) Grupo Newsan: la mayor parte de las operaciones de este grupo se encuentran en Ushuaia, donde, hace algunos años, desarrolla una nueva unidad de negocios con el objetivo de contribuir al cuidado del ambiente y disminuir los residuos derivados de la producción. A través de la iniciativa, Disposición Final Responsable, en alianza con la empresa PULPO, la firma inauguró una planta dedicada al reciclado de materiales de descarte, con el fin de disminuir, reciclar y reutilizar los residuos derivados de la producción. Desde el 2013, lograron recuperar material de descarte que hubiese ocupado $240000 \mathrm{~m}^{3}$, equivalente a 4000 contenedores de 40 pies. Newsan también cuenta con el programa Oficina Verde, que busca contribuir con una cultura organizacional respetuosa del ambiente y generar alianzas con proveedores no tradicionales.

k) Mastellone Hnos.: recicla un $69 \%$ de los residuos que genera en la totalidad de las plantas, disponiendo en relleno sanitario solo un $28 \%$ del total. Para ello, incorporaron en la cadena a los recicladores informales de residuos sólidos urbanos en el Depósito Albariño, con intenciones de disminuir la cantidad de residuos a disponer en un relleno sanitario y promover, además, la inclusión social. El $43 \%$ de los residuos

49 Jorge Luis Velázquez, "Qué es y cómo ganar plata con la economía circular”, El Cronista, 21 de jul. de 2017, acceso el 5 de julio de 2018, https://www.cronista.com/3dias/Que-es-y-como-ganar-plata-con-la-economia-circular-20170721-0038. html

50 Augusto Ferroni, "Recolección y reciclado de botellas PET: hacia una economía circular", Punto a punto, 18 de oct. de 2016, sección Fresh News, acceso 22 de julio de 2018, http://puntoapunto.com.ar/recoleccion-y-reciclado-de-botellas-pet-hacia-una-economia-circular/ 
generados son enviados a una cooperativa habilitada para tal fin. En el Complejo Industrial Pascual Mastellone, cada año se busca superar en un 80 \% la generación de residuos reciclables sobre los no reciclables, disminuyendo los gases de efecto invernadero. En este sentido, en el año 2015, se reciclaron el $88 \%$ de los residuos y el 30 $\%$ del agua utilizada en dicho complejo. Además, derivaron 72 toneladas de residuos destinados al relleno sanitario para ser utilizados como combustible alternativo en hornos rotativos cementeros.

1) Clorox hace su aporte a la economía circular desde un modelo de reciclaje inclusivo. La empresa nació en 1994 como continuadora de la firma Progar S. A., que ya comercializaba la lavandina Ayudín desde 1986, cuando se asoció con The Clorox Company, una compañía multinacional con una trayectoria de 100 años. Su propuesta de reciclaje promueve una sinergia entre distintos actores sociales, a saber: el Consejo Nacional de Investigaciones Científicas y Técnicas (Conicet) desarrolla contenidos y brinda capacitaciones en la separación de los residuos; la cooperativa Reciclando Sueños, que gestiona los residuos de la planta radicada en Aldo Bonzi, Partido de la Matanza, Provincia de Buenos Aires, capacita a los empleados y a la comunidad; el Organismo Provincial para el Desarrollo Sostenible OPDS y el Centro Ambiental de Reconversión Energética del municipio de La Matanza (CARE) acompañan e impulsan el proyecto; y los empleados de Clorox forman parte del voluntariado con escuelas de la comunidad. Durante el primer semestre del año 2016 llevaron el proyecto de Reciclaje Inclusivo desde el interior de la empresa hacia la comunidad. Mediante un programa de voluntariado, trabajaron en la capacitación de vecinos, docentes y alumnos de Aldo Bonzi. A su vez, se instalaron puntos limpios en diferentes escuelas, con el objetivo de que la cooperativa retire los reciclables de estos lugares, generando un circuito que se inicia en la planta productiva de Clorox y termina en la comunidad para cerrar el círculo.

m) Minidest: el proyecto de la empresa, reconocido con Medalla Dorada a la innovación agroindustrial en la edición 2017 de los premios de Expoagro, construye minidestilerías automatizadas y las opera de manera remota. Una planta, que funciona todo el año, procesa unas 1500 ha de maíz por año y proporciona alimento para unos 10000 animales/año. Según estudios del INTA, con estas plantas en el campo se ahorra, con cada camión de etanol producido, tres fletes de maíz y tres fletes de burlanda. ${ }^{51}$

51 Guillermo López, "Minidest es un ejemplo de economía circular" (José A. Porta - Nuevos Proyectos), Infonegocios, 12 de oct. de 2017, acceso el 7 de julio de 2018, https://infonegocios.info/40-de-las-grandes/minidest-es-un-ejemplo-de-economia-circular-jose-a-porta-nuevos-proyectos 


\section{CONCLUSIÓN}

El presente trabajo comenzó con un análisis de la crisis en la cual el planeta se encuentra inmerso debido a la extracción desmesurada de los recursos naturales y a la destrucción de los ecosistemas, propia de la economía lineal convencional dominada por una visión antropocéntrica. Actualmente casi nadie pone en tela de juicio la necesidad de emprender acciones para morigerar, o en el mejor de los casos, revertir esa alarmante situación. El problema radica en determinar cuál es el camino y no emprender medidas que sean ilusorias. Con este norte es que en esta primera parte se analizaron los principios y caracteres de la economía circular, finalizando con la descripción de una selección de programas, planes e iniciativas empresariales a nivel nacional que reflejan la implementación de acciones bajo su enfoque. A su vez se identificaron las diferentes escuelas de pensamiento que confluyeron en la economía circular, sus coincidencias y diferencias, fundamentalmente en el rol de la naturaleza y en la función de los ecosistemas, notando que la mayoría de ellas subordinan el sistema económico al entorno, pero la economía circular presenta las tres dimensiones en igualdad de condiciones y promueve la rentabilidad de las empresas. También se detallaron las críticas a este nuevo tipo de economía, básicamente provenientes de la teoría del decrecimiento, las que no pueden ser obviadas, así como tampoco sus beneficios. Si bien lo ideal sería limitar ese consumismo propio de la economía actual —el consumir por consumir - resulta arriesgado someter la supervivencia del planeta exclusivamente a las pautas del consumidor medio y para cambiar esas tradiciones, hábitos y costumbres tan arraigadas en las empresas y en los consumidores, se necesitarán años y años de educación; es un plan a largo plazo, además de prever la manera de solucionar el desempleo propio de una economía decreciente. En este marco, la economía circular se presenta como una respuesta atractiva, global y actual a la problemática, vale decir que ya se está implementando en varios sectores y que es bien acogida tanto por las empresas, por los consumidores y por las autoridades nacionales, regionales e internacionales, debido en gran parte a la conjunción de factores sociales y tecnológicos. La circularidad no es solo reciclar, es mucho más abarcadora, y se inicia en el mismo momento del diseño del producto, para que el mismo pueda ser reutilizado sucesivas veces, en donde los residuos son nutrientes, fomentando las energías renovables. Las mismas empresas reconocen la necesidad de integrar economía y sustentabilidad como parte de un circulo virtuoso y paulatinamente abandonan el proceso lineal "extraer-fabricar-consumir-eliminar" para abrazar el proceso circular de "refabricar, reacondicionar y reciclar — las tres R_". Por otra parte, un nuevo modelo de consumo está emergiendo, bajo el cual una nueva generación de consumidores prefiere los servicios que les permiten acceder a productos como usuarios, en lugar de apropiarse de estos, como propietarios. Los modelos de uso cooperativo o las redes de colaboración y uso compartido que generan más interacción entre los usuarios, vendedores, están en aumento, surgiendo la figura del prosumidor. La consigna es que los bienes de hoy sean los recursos de mañana, donde no existe basura porque todo integra un ecosis- 
tema que se reconstituye. Otros ejes importantes del cambio abarcan desde la producción, ya que los bienes se producen para durar, hasta el consumo, ya que se fomenta la economía colaborativa, que lleva a compartir el uso de bienes y servicios. En este trabajo, se aportaron ejemplos que demuestran que se puede generar valor a partir de la basura. Ese modelo se traspone a muchas escalas, desde la fabricación de prendas de vestir, calzado, e incluso muebles y elementos de decoración, hasta vehículos y edificios. Intervenir en sus procesos de fabricación, distribución y transporte, funcionamiento y fin de vida puede ser efectivo si el objetivo es reducir consumo de recursos — agua, energía y materias primas - y limitar residuos y emisiones. Además, se destacó la generación de inversiones y fuentes de trabajo. Desde esta perspectiva, el reciclado es una actividad fundamental ya que va configurando la nueva economía, una economía que sea sustentable.

Reviste importancia que los Gobiernos asuman su responsabilidad ya que últimamente se presentaron prácticas empresariales que simulan ser respetuosas del ambiente, se maquillan de verde, utilizan términos como eco o bio, pero en realidad siguen siendo altamente lineales. En ese sentido es necesario avanzar en el dictado de leyes que regulen la transición hacia una economía circular que fomente dichas prácticas y que sancione las lesivas a los ecosistemas.

Justamente la segunda parte del artículo, al cual las autoras invitamos a los lectores, se dedicará al estudio y análisis del marco normativo interno, regional e internacional vigente en el seno de la Unión Europea, sus Estados miembros, China (pionera en la temática), Argentina, Uruguay, entre otras iniciativas.

Es ilustrativo mencionar el concepto del "fideicomiso" de Gandhi, quien resalta la idea de que el ser humano es custodio de las dotaciones que posee la tierra y, por ende, no es su "propietario", sino su "fideicomisario", y la gestiona hoy para toda la especie humana y para las generaciones venideras. Es importante que la humanidad tome conciencia de que el planeta es un préstamo de las generaciones futuras y no una herencia de los antepasados.

\section{REFERENCIAS}

- "Argentinos que fabrican ladrillos con botellas recicladas y ganaron un premio de Google”. La Nación, 16 de nov. de 2017, sección Sociedad/Ecología. Acceso el 10 de julio de 2018. http://www.lanacion.com.ar/2082927-argentinos-que-fabrican-ladrillos-con-botellas-recicladas-y-ganaron-un-premio-de-google

- "Bienvenidos a la economía azul". Ecointeligencia (2012). Acceso 15 de junio de 2018. https://www.ecointeligencia.com/2012/05/economia-azul-gunter-pauli/ 
- Braungart, Michael y William McDonough. Cradle to Cradle (De la cuna a la cuna): rediseñando la forma en que hacemos las cosas. Madrid: McGraw-Hill, 2005.

- Castro, Meri. "Las zapatillas ecológicas confeccionadas por presos". La Nación. Revista Brando (10 de oct. de 2017). Acceso el 20 de julio de 2018. http://www.lanacion.com. ar/2070893-las-zapatillas-ecologicas-confeccionadas-por-presos

- Cerantola, Nicola. "Reflexiones sobre el pasado, presente y futuro de la economía circular". Revista Ambienta (2016).

- Comisión Europea. Comunicación de la Comisión al Parlamento Europeo. Hacia una economía circular: un programa de residuos cero para Europa. COM/2014/0398/FINAL. Bruselas: Comisión Europea, 2014.

- De Guillebon, Benoit. "Los 7 pilares de la economía circular". CEN Boletín de la Confederación de Empresarios de Navarra, Medio Ambiente (2014).

- Diotti, Carolina. Jornada sobre economía circular y objetivos de desarrollo sostenible 2030. Los verdes, 2017. Acceso el 28 de junio de 2018. http://www.losverdes.org.ar/jornada-economia-circular-objetivos-desarrollo-sostenible-2030/

- Ellen MacArthur Foundation. Growth Within: a Circular Economy Vision for a Competitive Europe. Reino Unido: Ellen MacArthur Foundation, SUN, McKinsey \& Co., 2015.

- Ellen MacArthur Foundation. Hacia una economía circular. Resumen ejecutivo. Reino Unido: Ellen MacArthur Foundation, 2014.

- Ellen MacArthur Foundation. Hacia una economía circular. Resumen ejecutivo. Reino Unido: Ellen MacArthur Foundation, 2017.

- Ellen MacArthur Foundation y World Economic Forum. Intelligent Assets: Unlocking the Circular Economy Potential. Reino Unido: Ellen MacArthur Foundation, 2016.

- Ferroni, Augusto. "Recolección y reciclado de botellas PET: hacia una economía circular". Punto a Punto, 18 de oct. de 2016, sección Fresh News. Acceso el 22 de julio de 2018. http://puntoapunto.com.ar/recoleccion-y-reciclado-de-botellas-pet-hacia-una-economia-circular/

- Grisbert Aguiar, Pepa. "El decrecimiento, camino hacia la sostenibilidad". El Ecologista (2007).

- Haas, Willi; Fridolin Krausmann, Dominik Wiedenhofer y Markus Heinzen. "How Circular is the Global Economy? An Assessment of Material Flows, Waste Production, and Recycling in the European Union and the World in 2005”. Journal of Industrial Ecology (2015). 
- Hathaway, Roy. “¿Es la economía circular alcanzable o deseable?”. Economía circulary minería urbana (2014). Acceso el 30 de abril de 2018. https://mineriaurbana.org/2014/08/12/ es-la-economia-circular-alcanzable-o-deseable/

- Instituto Nacional de Tecnología Agropecuaria. Proyecto Específico Tecnologías de Preservación de Alimentos y Aprovechamiento de Subproducto del Programa Nacional de Agroindustria y Agregado de Valor. Acceso el 20 de febrero de 2018. https://inta.gob.ar/proyectos/PNAIyAV-1130033

- ISO. Gestión ambiental - Integración de los aspectos ambientales en el diseño y desarrollo de productos. ISO/TR 14062:2002(es). Acceso el 21 de marzo de 2018. https://www.iso.org/

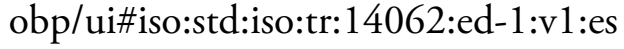

- ISO. Sistemas de Gestión ambiental - Directrices para la incorporación del ecodiseño. ISO 14006:2011(es). Acceso el 21 de marzo de 2018. https://www.iso.org/obp/ui/\#iso:std:iso:14006:ed-1:v1:es

- "La cerveza retornable, nuestra primera economía circular". La Nación, 5 de jun. de 2016, sección Economía. Acceso el 5 de julio de 2018. http://www.lanacion.com. ar/1905480-la-cerveza-retornable-nuestra-primera-economia-circular

- Latouche, Serge. La apuesta por el decrecimiento: ¿Cómo salir del imaginario dominante? Barcelona: Icaria Editorial, 2008.

- López, Guillermo. "Minidest es un ejemplo de economía circular (José A. Porta - Nuevos Proyectos)". Infonegocios, 12 de oct. de 2017. Acceso el 7 de julio de 2018. https://infonegocios.info/40-de-las-grandes/minidest-es-un-ejemplo-de-economia-circular-jose-a-porta-nuevos-proyectos

- Lovins, Amory; Hunter Lovins y Paul Hawken. "La ruta hacia el capitalismo natural". Harvard Business Review. Reprint Number 99309 (1999). Acceso el 9 de abril de 2018. https://www.terra.org/data/capitalismo_nat.pdf

- Lyle, John. Regenerative Design for Sustainable Development. New York: Wiley and Sons, 1994.

- Manzoni, Carlos. "Los celulares 'refabricados' ganan mercado en el país”. La Nación, 22 de oct. de 2017, sección Economía/Negocios. Acceso el 29 de junio de 2018. http://www. lanacion.com.ar/2074235-los-celulares-refabricados-ganan-mercado-en-el-pais

- Martínez, Adriana y Adriana Porcelli. "Reflexiones sobre la economía verde. El New Deal Ecológico Mundial". Revista de la Facultad de Derecho y Ciencia Politica de la Universidad Alas Peruanas 15, 19 (2017): 361-408. doi:http://dx.doi.org/10.21503/lex.v15i19.1383

- Martínez Camarero, Carlos. "Más allá del reciclaje, avanzar hacia la producción limpia, el ecodiseño y los biomateriales". Daphia (2016). Acceso el 15 de mayo de 2018. http:// 
www.daphnia.es/revista/64/articulo/1258/Mas-alla-del-reciclaje-avanzar-hacia-la-produccion-limpia-el-ecodisenyo-y-los-biomateriales.

- Nilus. Tecnología al rescate de los alimentos. Acceso el 22 de julio de 2018. https://www. nilus.org/

- Organización de las Naciones Unidas para la Alimentación y la Agricultura. Pérdidas y desperdicio de alimentos en el mundo - Alcance, causas y prevención. Roma: FAO, 2012.

- Organización de las Naciones Unidas para la Alimentación y la Agricultura. Informe final diseño metodológico para la estimación de los desperdicios de alimentos de la Argentina en las etapas de distribución y comercio minorista, y consumo en el hogar. Buenos Aires: Organización de las Naciones Unidas para la Alimentación y la Agricultura, 2017.

- Pérez, Marina. "Biomimesis: cómo la naturaleza soluciona nuestros problemas". Fundación Melior. 2012. Acceso el 7 de mayo de 2018. http://www.fundacionmelior.org/content/tema/biomimesis-como-la-naturaleza-soluciona-nuestros-problemas

- Programa de Naciones Unidas para el Medio Ambiente. Extracto del informe desacoplar el uso de los recursos naturales y los impactos ambientales del crecimiento económico. 2011. Acceso el 21 de mayo de 2018. https://www.zaragoza.es/contenidos/medioambiente/onu/349spa-sum.pdf

- Programa de las Naciones Unidas para el Medio Ambiente. Hacia una economía verde: guia para el desarrollo sostenible y la erradicación de la pobreza. Síntesis para los encargados de la formulación de políticas. New York: Programa de las Naciones Unidas para el Medio Ambiente, 2011.

- Programa de las Naciones Unidas para el Medio Ambiente. Descubriendo los caminos hacia una economía verde e inclusiva. Resumen ejecutivo. Ginebra: Programa de las Naciones Unidas para el Medio Ambiente, 2015.

- Provincia de Buenos Aires. Organismo Provincial para el Desarrollo Sostenible. La Provincia dio el primer paso hacia una economía circular. 2016. Acceso el 13 de mayo de 2018. http://wwwa.opds.gba.gov.ar/index.php/articulos/ver/1243

- Ramos Martín, Jesús “Economía biofísica”. Investigación y Ciencia (2012).

- Rifkin, Jeremy. La era del acceso. La revolución de la nueva economía. España: Paidós, 2000.

- Rosemberg. Adrián. "Ecología y simbiosis industrial: Nuevos conceptos que agregan valor al relacionamiento productivo". Revista Virtual Pro. Ecología industrial (2008). Acceso el 23 de junio de 2018. https://www.revistavirtualpro.com/revista/ecologia-industrial/4

- Stahel, Walter. The Performance Economy. Hampshire: Palgrave Macmillan, 2010. https://doi.org/10.1057/9780230288843 
- Tuchín, Florencia. "Hacia una economía circular". El Cronista, 20 de oct. de 2016. Acceso el 10 de febrero de 2018. http://www.cronista.com/responsabilidad/Hacia-una-economia-circular-20161020-0024.html

- United Nations, Department of Economic and Social Affairs, Population Division. World Population Prospects: The 2017 Revision, Key Findings and Advance Tables. New York: United Nations, 2017. https://doi.org/10.18356/b19523c6-en

- Valls, Mariana. “¿Cuánto ambiente desperdiciamos para producir los alimentos que no se consumen? ¿Es realmente necesario duplicar la producción de alimentos para satisfacer las necesidades de nuestra población creciente?”. El Dial.com Biblioteca Jurídica Online (2017). elDial DC23CA.

- Velázquez, Jorge Luis. "Qué es y cómo ganar plata con la economía circular”. El Cronista, 21 de jul. de 2017. Acceso el 5 de julio de 2018. https:/www.cronista.com/3dias/Que-esy-como-ganar-plata-con-la-economia-circular-20170721-0038.html

- World Wildlife Fund. Report Green - Game Changes. Reino Unido: WWF, 2012.

RECIBIDO: 02/07/2018

APROBADO: $14 / 09 / 2018$ 


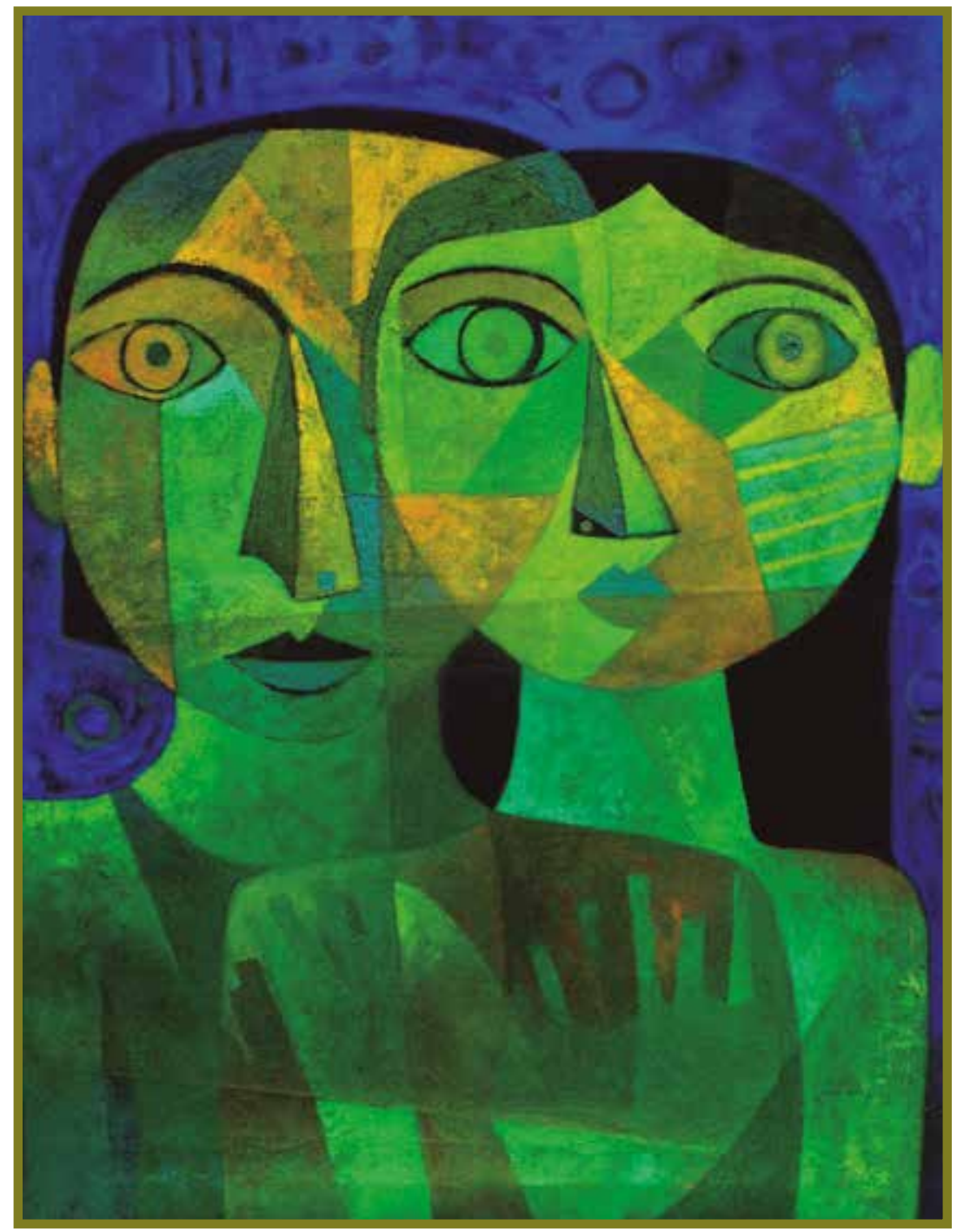

Esperanza. Pintura. Juan Carlos Nanañake. 